\title{
The iCook 4-H Study: Report on Physical Activity and Sedentary Time in Youth Participating in a Multicomponent Program Promoting Family Cooking, Eating, and Playing Together
}

Kendra K. Kattelmann, PhD, RDN, LN, FAND ${ }^{1}$; Jessica R. Meendering, PhD, EP-C ${ }^{1}$; Emily J. Hofer, MS, RD, LN ${ }^{1}$; Chase M. Merfeld, MS, RD, LN ${ }^{1}$; Melissa D. Olfert, DrPH, RDN ${ }^{2}$; Rebecca L. Hagedorn, $\mathrm{BS}^{2}$; Sarah E. Colby, $\mathrm{PhD}, \mathrm{RD}^{3}$; Lisa Franzen-Castle, $\mathrm{PhD}, \mathrm{RD}^{4}$; Jonathan Moyer, $\mathrm{MS}^{5}$; Douglas R. Mathews, $\mathrm{PhD}, \mathrm{RD}^{6}$; Adrienne A. White, PhD, RDN, FAND ${ }^{6}$

\begin{abstract}
Objective: To report physical activity and sedentary time outcomes of youth in $i$ Cook 4-H.

Study Design and Setting: $i$ Cook 4- $H$ was a 5-state, randomized, control-treatment, family-based childhood obesity prevention intervention promoting cooking, eating, and playing together.

Participants and Intervention: Youth aged 9-10 years and the main preparer of their meals participated in the 12-week program followed by monthly newsletters and biyearly booster sessions until 24 months.

Main Outcome Measure(s): A total of 155 youth were fitted with an Actigraph GT3X+ accelerometer, which they wore for 7 days at baseline and 4, 12, and 24 months to measure mean daily minutes per hour of waking wear time for sedentary time (ST), light physical activity (PA) (LPA), moderate PA, vigorous PA, and moderate to vigorous PA. Self-reported PA was assessed using the Block Kids Physical Activity Screener and additional questions querying for the program goal of the frequency of family actively playing together. Linear mixed models were used to determine differences from baseline to 24 months. Significance was set at $P \leq .05$. Results: There was a significant $(P<.05)$ group $\times$ time interaction for LPA (adjusted interaction B estimate, 95\% confidence interval; $0.18[0.05,0.30])$ and ST $(-0.15[-0.26,-0.04])$; ST increased and LPA decreased in the treatment group. There were no differences in other accelerometer-derived PA measures, self-report Block Kids Physical Activity Screener measures, or frequency of family actively playing together at any time point.

Conclusions and Implications: $i$ Cook $4-H$ was a multicomponent program observing youth aged 9-10 years for 24 months that focused on enhancing cooking skills, mealtime behavior and conversation, and PA through daily family activities. Greater emphasis on developing PA skills, changing environmental factors, and increasing PA both in and after school may be needed.

Key Words: family-based obesity prevention intervention, physical activity, sedentary time, youth $(J$ Nutr Educ Behav. 2019; 51:S30-S40.)
\end{abstract}

Accepted September 6, 2018. Published online December 1, 2018.

\footnotetext{
${ }^{1}$ Department of Health and Nutritional Sciences, South Dakota State University, Brookings, SD

${ }^{2}$ Division of Animal and Nutritional Sciences in Human Nutrition and Foods, West Virginia University, Morgantown, WV

${ }^{3}$ Department of Nutrition, University of Tennessee, Knoxville, TN

${ }^{4}$ Nutrition and Health Sciences Department, University of Nebraska-Lincoln, Lincoln, NE

${ }^{5}$ Department of Biostatistics and Epidemiology, School of Public Health and Health Sciences, University of Massachusetts, Amherst, MA

${ }^{6}$ School of Food and Agriculture, University of Maine, Orono, ME

Conflict of Interest Disclosure: The authors have not stated any conflicts of interest.

The publication of this supplement to the Journal of Nutrition Education and Behavior, including this article, was supported by the National Institute of Food and Agriculture, US Department of Agriculture, under award number 2012-68001-19605. This article underwent the usual peerreview process followed by the journal.

Address for correspondence: Kendra K. Kattelmann, PhD, RDN, LN, FAND, Department of Health and Nutritional Sciences, South Dakota State University, Box 2275A, Wagner 425, Brookings, SD 57007; E-mail: kendra.kattelmann@sdstate.edu

(C) 2019 The Authors. Published by Elsevier, Inc. on behalf of the Society for Nutrition Education and Behavior. This is an open access article under the CC BY license. (http://creativecommons.org/licenses/by/4.0/)

https://doi.org/10.1016/j.jneb.2018.09.002
} 


\section{INTRODUCTION}

Childhood obesity is a significant problem in the US. ${ }^{1}$ Despite recent declines in certain age groups, $34.2 \%$ of youth aged 6-11 years remain overweight or obese. ${ }^{1}$ Childhood obesity is influenced by demographic factors and eating behaviors as well as a lack of physical activity (PA). ${ }^{2,3}$ Overweight and obese children are at increased risk for health consequences including high blood pressure, insulin resistance, type 2 diabetes, elevated cholesterol, cardiovascular disease, and some cancers. ${ }^{4,5}$ The World Health Organization suggests that overweight and obese children and adolescents will grow into overweight and obese adults, leading to an increased number of health concerns later in life. ${ }^{4}$ This assumption is in line with results from a systematic review that reported an association between overweight and obesity in childhood and an increased risk for type 2 diabetes, hypertension, coronary heart disease, and mortality in adulthood. ${ }^{6}$ McLoone and Morrison ${ }^{7}$ also reported that as the body mass index (BMI) of the parent increased, so too did the prevalence of obesity in the child, which suggests a need for interventions aimed at both the parent and child.

Although some causes and consequences of childhood obesity are known, the most effective way to prevent childhood obesity is still debated. It is known that increasing PA can have an important role in preventing childhood obesity. ${ }^{8,9}$ Cited benefits of PA for children include maintenance of a healthier weight, better coordination and movement, healthier musculoskeletal tissues, and a healthier cardiovascular system. ${ }^{8,9}$ Maintaining a healthy weight can also improve self-esteem and body image. ${ }^{5,10}$ According to the 2008 Physical Activity Guidelines for Americans, children and adolescents should engage in at least 60 minutes of moderate to vigorous PA (MVPA) each day to prevent the risk for chronic diseases. ${ }^{8}$ Moderate to vigorous $\mathrm{PA}$ includes activities such as biking, running, or jumping rope and is defined as an effort of 5-8 on a scale of $0-10 .^{8}$ However, despite this recommendation, most children and adolescents in the US do not meet the guidelines. ${ }^{11-15}$ In 2008, Troiano and colleagues ${ }^{14}$ reported that $58 \%$ of youth aged 6 -11 years did not meet the guidelines and in 2012, Fakhouri and colleagues ${ }^{15}$ reported that $75.2 \%$ of those aged 12-15 years did not meet them. These results indicate that there is a decline in PA that occurs with age, which was also confirmed by Belcher and colleagues. ${ }^{16}$ Furthermore, the lack of PA in adolescents is not limited to those in the US. It was estimated that internationally, only $9 \%$ of boys and $1.9 \%$ of girls aged 5-17 years are achieving $60 \mathrm{~min} / \mathrm{d}$ MVPA. ${ }^{12}$

It was reported that children aged 6-11 years spend an average of 6 hours in sedentary time such as sitting and watching TV. ${ }^{17}$ Reducing sedentary time may also have a role in decreasing and preventing childhood obesity independently of PA. Examples of sedentary behaviors include sitting, sleeping, lying down, and reclining, which are often activities that children do while watching TV or playing video games. ${ }^{18,19}$ Similar to the consequences of low PA, sedentary time is negatively associated with metabolic outcomes. ${ }^{20,21}$ Multiple studies found a positive association between reduced sedentary time and markers associated with health outcomes such as improved insulin sensitivity and lipid levels. ${ }^{22-24}$ It was also shown that spending $\geq 2 \mathrm{~h} / \mathrm{d}$ watching TV is related to excess weight gain and fat mass. ${ }^{17}$ In the most recent guidelines from the Academy of Pediatrics, recommendations for parents are to provide consistent limits regarding media use and to ensure that media use does not interfere with adequate sleep, PA, and other activities related to health behaviors. ${ }^{25}$

Currently, 2 types of interventions, school- and family-based, aim to increase PA and reduce sedentary time to address childhood obesity.,26-39 Although some school-based interventions had positive outcomes, they tended to lack long-term impacts and were reported to be more successful when the parent or family was involved. ${ }^{26,31,33}$ Studies from Khambalia and colleagues ${ }^{26}$ and Li and colleagues ${ }^{27}$ both concluded that school- based interventions were more effective when they included a family component. There is strong support in the literature for inclusion of a familybased component to interventions aimed at increasing PA and reducing sedentary time. ${ }^{29-37}$ Family-based interventions may lead to longer-term success because of parental involvement, which transitions the learned behavior into the home. ${ }^{29,30,33}$ It is also known that children model the behaviors of their parents, which underlines the need for family-based obesity interventions. ${ }^{34-37}$ Brown et $\mathrm{al}^{38}$ reported in a systematic review that families that included goal setting and planning for PA had increased motivation and changes in PA levels. Recent literature suggested that multicomponent programs such as those including segments on nutrition, PA, and cooking tend to be more successful as well. ${ }^{29,39-41}$

There is a need for effective multicomponent, family-based interventions to promote healthful behaviors to enhance obesity prevention throughout life. ${ }^{29,34,26-39,42-45}$ The iCook $4-H$ program was developed to meet this need. iCook $4-H$ was a 12 week, multicomponent, family-based obesity prevention intervention aimed at increasing basic cooking skills, family mealtimes, and PA in youth aged 9-10 years. This article reports PA and sedentary time outcomes of participants in the intervention.

\section{METHODS}

The intervention was a control-treatment design for youth aged 9-10 years and the preparer of their main meal; it took place in Maine, Nebraska, South Dakota, Tennessee, and West Virginia. A community-based participatory research approach was used to design, implement, and evaluate the intervention. Steering committees were formed in each state and included members from the research team, extension/4-H staff, Expanded Food and Nutrition Education Program staff (EFNEP), community members, and graduate students.

To build the curriculum, the researchers employed the 4 - $\mathrm{H}$ model of empowering youth to reach their full potential by working and learning in partnership with caring 
adults. ${ }^{46}$ By using the 4 - $\mathrm{H}$ model as the basis for the $i$ Cook 4-H program, youth and adults were encouraged to work together while learning new skills and information. The EFNEP personnel were included in the program design to ensure that the curriculum was appropriate for EFNEP programming, which is typically aimed at low-income populations.

\section{iCook Leaders and Training}

Extension or EFNEP staff served as the iCook leaders, who were trained by the research staff on how to deliver the curriculum. To ensure that all leaders received the same training, the research staff developed and recorded training modules. Fidelity of delivery of the curriculum was measured during the intervention; $\geq 90 \%$ of all lessons were delivered as planned.

\section{Recruitment and Participant Selection}

Session leaders recruited participants using flyers, newspaper advertisements, word of mouth, and social media. The following locations were targeted: community organizations, schools, churches, local businesses, 4-H and extension offices, and medical offices and clinics. Recruitment was aimed at low-income and/or rural populations and occurred in late spring and summer, 2013 with the goal of recruiting the sample before the start of September, 2013. Participating youth had to be aged 9 years before the program began in September, 2013 and had to be aged $<11$ years before December 31, 2013. In addition, youth-adult pairs were eligible to participate only if they were free of food allergies or medical and physical limitations that would hinder participation, were willing to eat meat and dairy, and had access to the Internet in their home. Participants did not have to be current 4-H members or participants in any EFNEP program to participate in the iCook 4-H program.

A goal of 500 youth-adult pairs (100/state) was set when the study began. Pairs were to be assigned to control or treatment as they confirmed participation in the study, based on random number assignment. Power calculations for the goal sample size were computed for the iCook 4- $H$ primary outcome of youth BMI at 24 months. Sample size was calculated to detect a BMI change of -0.85 difference in mean BMI with a significance of $P \leq .05$ and power of 0.8 , resulting in a sample size of 274 . An initial sample of 500 youth (100/ state) was desired to account for an attrition of $20 \%$ expected at 4 months and $30 \%$ at 12 and at 24 months. However, recruitment did not yield the desired number of participants; thus, a protocol change was made to the random number generator, assigning 2 participants to treatment for every 1 control participant with the goal of having more treatment than control participant dyads. Both control and treatment group youth participated in anthropometric and survey assessments at 4 time points: $0,4,12$, and 24 months. The 0-month assessment was the baseline and occurred in August, 2013 before the intervention began. Treatment youth participated in the iCook intervention. The control youth received only the assessments.

All youth participants provided verbal assent and parents provided written informed consent. The study was approved by the institutional review board for the protection of human subjects in each participating state university (Maine, Nebraska, South Dakota, Tennessee, and West Virginia).

\section{iCook 4-H Intervention}

The $i$ Cook 4- $H$ intervention included 6 sessions, each 2 hours long, over 12 weeks from September to December, 2013 in all 5 participating states. The curriculum was developed using Social Cognitive Theory ${ }^{47}$ and focused on basic cooking skills, family mealtime, PA, and goal setting in an effort to teach youth-adult pairs to cook, eat, and play together. iCook 4$H$ was designed as a biweekly curriculum so that participants were allowed time between sessions to apply learned skills and behaviors before returning for another lesson.

During an iCook 4- $H$ session, participants were taught a cooking skill (s), allowed to apply the skill(s) to make a recipe, participate in family mealtime and a 15- to 20-minute PA session, and then conclude by setting goals together as a family. Additional information about the curriculum development is available. ${ }^{48}$ The team developed the PA components by adapting components of the existing 4-H curriculum Youth in Motion ${ }^{49}$ and resources used in physical education -teacher education curriculum. The activities were designed to promote PA and decrease sedentary behavior through daily lifestyle activity. Youth-adult pairs were taught the importance of PA as well as ways to be physically active together in an everyday setting. Some activities encouraged increasing PA through games that could be played in the home whereas others taught behaviors to reduce sedentary time by demonstrating how to incorporate movement through daily chores. All activities focused on setting weekly goals to increase activity and perform the activities as a family. Table 1 provides a brief description of PA lessons. The number of pairs per session was limited to 6 , for a total of 12 participants including youth and adults.

Another key component of the iCook 4- $\mathrm{H}$ intervention was a secure website where treatment participants from all 5 states could interact. Youth were encouraged to share videos and pictures of them using their new cooking skills or participating in PA at home. All youth were provided with a video camera to record activities and were shown how to upload videos and pictures to the website. iCook $4-H$ leaders instructed youth-adult pairs to share 1 video or picture per week on the interactive website.

To keep treatment participants engaged in $i$ Cook $4-H$, the interactive website remained in use until the 24-month follow-up assessment. Monthly challenges for cooking and PA encouraged youth to continue posting pictures or videos on the website. Any youth who posted a picture or video for the challenge was entered into a drawing for a \$25 or \$50 gift card; 1 winner was chosen for each challenge monthly.

In addition to the website, a monthly newsletter that included the monthly challenge winners as well as healthy recipes and word 
Table 1. Physical Activity Components of iCook Lessons

\begin{tabular}{|c|c|c|c|}
\hline iCook Lessons & Physical Activity & $\begin{array}{c}\text { Intensity of } \\
\text { Physical Activity }\end{array}$ & Description \\
\hline 1 & $\begin{array}{l}\text { Getting to Know } \\
\text { You Circle Game }\end{array}$ & Light & $\begin{array}{l}\text { Adult and children play a getting-to-know-you circle game to } \\
\text { promote activity in a small space. A plate is taped on the } \\
\text { floor for each participant in a large circle. One participant } \\
\text { starts off by standing in the center of the circle and states } \\
\text { something about himself or herself. All participants who } \\
\text { agree with the statement must run across the circle to a dif- } \\
\text { ferent spot. Whoever is left without a spot at a plate is now } \\
\text { in the center of the circle. }\end{array}$ \\
\hline 2 & Know Your Heart Rate & Moderate & $\begin{array}{l}\text { Adults and children learn how to measure heart rate after } \\
\text { completing different levels of physical activity (resting, } \\
\text { walking, jogging, and sprinting). Additional instruction } \\
\text { includes the importance of physical activity. }\end{array}$ \\
\hline 3 & Charades Game & Light & $\begin{array}{l}\text { Adult and participant identify and practice movements for } \\
\text { normal household chores. Split participants into } 2 \text { teams. A } \\
\text { participant from } 1 \text { team chooses a slip of paper with the } \\
\text { household chore listed from a container and must perform } \\
\text { the activity for his or her team to guess without using } \\
\text { words. The activity demonstrates the importance of activity } \\
\text { in daily living. }\end{array}$ \\
\hline 4 & Stretching & Light & $\begin{array}{l}\text { Participants focus on learning how to stretch different } \\
\text { muscles in their body (bicep, triceps, chest, inner thigh, } \\
\text { lower back, and hamstring). }\end{array}$ \\
\hline 5 & iCook Shuffle & Moderate & $\begin{array}{l}\text { Adult and participant discuss how to decrease sedentary } \\
\text { behavior and are taught simple activities that can be com- } \\
\text { pleted in the home without expensive equipment. Split par- } \\
\text { ticipants into } 2 \text { teams. Each participant is given a beanbag } \\
\text { and places it on top of their feet. They must then race each } \\
\text { other by shuffling their feet so that the beanbag does not } \\
\text { fall off. }\end{array}$ \\
\hline 6 & Cup Stacking Game & Light & $\begin{array}{l}\text { Adults and participants are provided with additional exam- } \\
\text { ples of simple games that can be played with inexpensive } \\
\text { items. Split participants into } 2 \text { teams. Twelve cups are } \\
\text { placed in a single stack on } 2 \text { tables at } 1 \text { end of the room. } \\
\text { Each team stands in a line across the room from the table. } \\
\text { A participant runs to the table and stacks the cups into a } \\
\text { pyramid and then collapses the pyramid and places the } \\
\text { cups back into a single stack. Then, they run back to their } \\
\text { team and tag the next person in line to go next (relay race). }\end{array}$ \\
\hline
\end{tabular}

searches was sent to treatment participants. Booster events were held twice each year for treatment participants so that youth could interact with other families in their sessions. The booster events focused on active play such as swimming or cooking events that included playing group games.

\section{Data Collection Procedures}

Control and treatment youth participated in assessments at 0 (baseline),
4, 12, and 24 months by trained researchers who took anthropometric measurements, collected accelerometer data, and administered surveys at each time point. Researchers explained to the youth how to complete the surveys and remained available for questions during completion of the surveys. The baseline assessments occurred before the intervention in August, 2013. Youth and adults were each compensated $\$ 10$ (\$20/pair) for their time in each of the 4 assessments.

\section{Anthropometric Assessments}

Anthropometric assessments included height and weight. Height measurements were taken twice and measured to the nearest $0.1 \mathrm{~cm}$ using a SECA 213 (Chino, CA) or Charder HM 200P (Issaquah, WA) portable stadiometer. Weight measurements were also taken twice and measured to the nearest $0.1 \mathrm{~kg}$ using a SECA 874 digital scale or HealthOMeter 752KL portable health scale (McCook, IL). Trained researchers took all measurements (interrater 
reliability of Pearson correlation coefficient $\geq 0.80$ ); the average of the 2 measurements for both height and weight was used. Instruments were calibrated before assessment.

\section{Accelerometer-Derived PA and Sedentary Time}

Physical activity and sedentary time were measured using accelerometers in a subset of the total sample of 228 control and treatment youth. A priori, the goal was set to fit $25 \%$ of the sample with accelerometers. However, based on a lower number of the total sample recruited than expected and timing of assessments, accelerometers were provided to the first 155 youth $(68 \%)$ to measure the frequency, duration, and intensity of activity. Selected youth were given an ActiGraph GT3X+ accelerometer (Pensacola, FL) on an elastic belt of their color choice, along with instructions on how to wear the accelerometer. Youth were instructed to wear the accelerometer for a set 7day period before the start of the classes; the device was collected after the seventh day.

A 15-second epoch was used to account for the intermittent and sporadic nature of PA patterns in children $^{50}$ and to align with the validation epoch length. ${ }^{51}$ Non-wear time was classified as 60 consecutive minutes with no activity counts, not allowing for interruptions. ${ }^{52,53}$ Daily wear time was calculated by subtracting non-wear time from 24 hours of that particular day. For a day to valid, subjects were required to accumulate $\geq 600$ minutes (10 hours) of wear time. ${ }^{14,54}$ A minimum of 4 valid days (3 valid weekdays and 1 valid weekend day) were required to meet weartime compliance. ${ }^{55,56}$ Cut points for accelerometer data were defined based on the number of activity counts per epoch, as defined by Evenson and colleagues ${ }^{57}$ : sedentary time, 0-16 counts; light PA (LPA), 17-382 counts; moderate PA (MPA), 383 -668 counts; vigorous PA (VPA), $\geq 669$ counts; and MVPA, $\geq 383$ counts. Minutes of wear time, sedentary time, LPA, MPA, VP, and MVPA were calculated per day and are presented as minutes per hour of wear time to standardize for wear time. ${ }^{58}$

\section{Self-Reported Assessment of PA}

Self-reported PA was measured in all control and treatment youth using the Block Kids Physical Activity Screener (BKPAS), a validated tool to measure self-reported PA in children aged 8-17 years. ${ }^{59}$ The tool uses a self-report of activity over the previous 7 days and provides information about the frequency and duration of MPA, VPA, MVPA, and recreational PA.

An additional self-reported measure of PA was a program evaluation survey created by the research team to assess for behaviors specifically encouraged in the lessons. The questions were tested for readability and understandability by a small sample of the target population before the intervention began. This evaluation was used to query youth on a scale of $1-5$; responses were coded as never $=1$, rarely $=2$, sometimes $=3$, most of the time $=4$, and always $=5$ for self-reported perception of frequency of family playing together and intensity and duration of PA. Physical activity questions on the program evaluation survey were:

- How often does your family play together actively?

- When you think about each day of the week, how often does your heart pump hard and do you sweat when you are being physically active?

- When you think about each day of the week, how often are you physically active for at least 60 minutes each day?

The program evaluation was completed at all assessment time points by treatment and control youth.

\section{Data Analysis}

The researchers used $\mathrm{R}$ data analysis software (version 3.2.3, Vienna, Austria, 2015) to calculate descriptive statistics and analyses for PA data. Linear mixed models were used to analyze accelerometer associations in minutes per hour of sedentary time and PA intensities, BKPAS, and PA program evaluation data at each time point. Fixed effects included group (treatment or control), time $(0,4,12$, and 24 months), and group $\times$ time interaction. Random effects included random intercepts and time slopes for individual youth. In addition to group, time, and group $\times$ time interaction, a set of potential confounders was considered for inclusion in the model as fixed effects (gender, ethnicity/race, state, etc). Potential confounders were included in the model using the best model for each variable with the lowest area under the curve. The $\beta$-estimate and $90 \%$ confidence interval for interaction terms are reported for adjusted and unadjusted models. Block Kids Physical Activity Screener data that were nonnormally distributed were transformed using square root calculation; differences were determined using the transformed data. $P \leq .05$ was set as statistically significant.

\section{RESULTS}

The iCook 4- $H$ program included a total of 228 youth-adult pairs (151 treatment and 77 control). Of the total sample, 155 (108 treatment and 47 control) were fitted with accelerometers and 122 (88 treatment and 34 control) met accelerometer compliance standards at baseline. Of these participants, $51 \%$ were female and 78\% were Caucasian (mean age, 9.4 years); approximately $62 \%$ were normal weight (Table 2). There were no differences in sex, race and ethnicity, and BMI between those who met accelerometer compliance standards and those did not. Moreover, there was no difference in BKPAS-measured $\mathrm{PA}$ in those who wore accelerometers and those who did not. In addition, the dropout rate did not differ between treatment and control participants (data not shown).

Table 3 lists mean minutes per hour of accelerometer-derived PA and sedentary time. Both the adjusted (controlling for gender, race, and socioeconomic status) and unadjusted models indicated a significant interaction between group and time for sedentary time and LPA. The treatment group sedentary time increased and LPA decreased whereas the control group remained the same for both variables over the 24 months. There were no significant interactions between group and time 
Table 2. Demographics of Youth Participants With Accelerometers in iCook 4-H

$\begin{array}{lcc}\text { Variable } & \begin{array}{c}\text { All Participants } \\ \text { Fitted With }\end{array} & \begin{array}{c}\text { Participants Who } \\ \text { Were Accelerometer } \\ \text { Compliant (n= 122) }\end{array} \\ \text { Female (\%) } & 51 & 46.7 \\ \text { Race (white) (\%) } & 78.5 & 78.1 \\ \text { Age (mean } \pm \text { SD) } & 9.4 \pm 0.6 & 9.4 \pm 0.6 \\ \text { State, n (\%) } & & 35(28.7) \\ \text { Maine } & 50(32.3) & 4(3.3) \\ \text { Nebraska } & 6(3.9) & 18(14.8) \\ \text { South Dakota } & 27(17.4) & 21(17.2) \\ \text { Tennessee } & 26(16.8) & 44(36.1) \\ \text { West Virginia } & 46(29.7) & \\ \text { Body mass index } & & 5(4.1) \\ \text { category, } n(\%) & 5(3.2) & 75(61.5) \\ \text { Underweight } & 96(61.9) & 19(15.6) \\ \text { Normal weight } & 23(14.8) & 23(18.9) \\ \text { Overweight } & 31(20) & \\ \text { Obese } & & \end{array}$

MPA, VPA, or MVPA in adjusted and unadjusted models. Table 3 lists mean minutes per day self-reported BKPAS data. There was a significant difference in VPA over time in the BKPAS data $(P=.02)$ : self-reported VPA increased in both groups from baseline to 24 months. There were no group $\times$ time interaction or group differences in the BKPAS.

Table 4 reports program evaluation survey response data. There were no significant differences for participants resulting from treatment in playing together with their families $(P=.08)$ and engaging in PA that made their heart pump more frequently $(P=.07)$ Both groups reported a slight increase $(P=.02)$ in how often they were physically active for at least $60 \mathrm{~min} / \mathrm{d}$.

\section{DISCUSSION}

The objective of the current study was to assess accelerometer-derived and self-reported PA and sedentary time from baseline ( 0 months) to 24 months in youth who participated in the iCook 4-H program. iCook $4-H$ was designed using Social Cognitive Theory specifically focusing on reciprocal modeling by parents and incorporated opportunities for youth to learn through observation and doing. Although the preparer of the main meal was required to attend the lesson and interact with the youth in setting goals and completing the curriculum activities, mean minutes per hour of PA decreased for all intensity levels and sedentary time increased for those in the treatment group, and there were no changes in the control group in accelerometer-derived data. With the exception of VPA, a similar pattern of PA was observed in the self-reported BKPAS. There were no differences in reported BKPAS recreational time, MPA, or MVPA. There was a decrease in PA and an increase in sedentary time for all youth. Although it was reported that parents may influence children's participation in PA by providing proper informational, emotional, appraisal, and instrumental support, such as enrolling children in the activity, ${ }^{60}$ this was not observed in the iCook $4-H$ program. This lack of change in measured PA may indicate that in addition to individual behavior, which was the focus of this program, inclusion of environmental and policy changes that support opportunities for PA may be needed to make longterm changes.

This decrease in PA that occurred with age in treatment youth is consistent with what others reported. ${ }^{12,16}$ Previous researchers looked at factors affecting activity levels and reported that age, sex, and type of activity all have a role in activity levels. An intervention by Vanhelst and colleagues $^{61}$ reported that the PA program was more effective for youth aged $<12$ years and suggested the need to aim PA interventions at younger age groups. Participants in iCook $4-H$ were aged 9-10 years when recruited. Results from the current study indicated that interventions might need to start even earlier. Vanhelst and colleagues also reported that team sports had better outcomes than net sports (ie, tennis) and activities should be age and/or sex specific to have the greatest impact. In addition, Jago and colleagues $^{62}$ reported that children wanted games that were challenging enough for them (age appropriate) and that they did not like elimination games such as dodgeball. Results from Jago and colleagues also suggested the need for age- and genderspecific PA programs. Although iCook 4-H PA was developmentally appropriate, the activities were not gender specific. The iCook $4-H$ activities focused on increasing activity through daily living such as chores and playing together, rather than specific PA programing such as the activity that occurs with organized sports.

It is also important to consider factors such as time spent in school, which can significantly influence activity levels. On average, children in the US spend the majority of their day (roughly $6.6 \mathrm{~h} / \mathrm{d}$ ) in school. ${ }^{63}$ Although schools provide multiple opportunities for students to be physically active, including physical education class, recess, standing desks, and activity breaks, these opportunities are not always used. Many schools do not have the budget or space for physical education classes and choose to cut recess time to allow for more time in the classroom. ${ }^{63-65}$ However, 3 of the 4 assessment times (baseline and 12 


\begin{tabular}{|c|c|c|c|c|c|c|c|c|c|c|c|c|c|}
\hline $\begin{array}{l}\text { Sedentary Time/ } \\
\text { Physical Activity }\end{array}$ & Group & \multicolumn{8}{|c|}{ Adjusted Means } & \multicolumn{2}{|c|}{$\begin{array}{c}\text { Interaction }(95 \% \mathrm{Cl}) \\
\text { Adjusted }\end{array}$} & \multicolumn{2}{|c|}{$\begin{array}{c}\text { Interaction }(95 \% \mathrm{Cl}) \\
\text { Unadjusted }\end{array}$} \\
\hline & Treatment & \multicolumn{2}{|c|}{$40.0(38.7,41.3)$} & \multicolumn{2}{|c|}{$41.8(40.4,43.3)$} & \multicolumn{2}{|c|}{$41.6(40.0,43.3)$} & \multicolumn{2}{|c|}{$44.2(42.2,46.2)$} & & & & \\
\hline \multirow[t]{2}{*}{ Light } & Control & \multicolumn{2}{|c|}{$15.4(13.9,6.8)$} & \multicolumn{2}{|c|}{$15.9(14.4,17.5)$} & \multicolumn{2}{|c|}{$15.9(14.0,7.7)$} & \multicolumn{2}{|c|}{$15.5(12.8,18.2)$} & \multicolumn{2}{|c|}{$-0.15(-0.26,-0.04)$} & \multicolumn{2}{|c|}{$-0.14(-0.24,-0.03)$} \\
\hline & Treatment & \multicolumn{2}{|c|}{$17.1(16.1,18.1)$} & \multicolumn{2}{|c|}{$15.6(14.4,16.7)$} & \multicolumn{2}{|c|}{$15.7(14.5,17.0)$} & \multicolumn{2}{|c|}{$13.6(12.0,15.3)$} & & & & \\
\hline Vigorous & Control & $0.8(0.6$ & & & $(0.7,1.2)$ & $0.8(0.5,1.1$ & & & $0.4,1.2)$ & $-0.01(-0.0$ & $0.01)$ & -0.01 & $-0.02,0.01)$ \\
\hline & Treatment & $0.9(0.8$ & & & $(0.6,1.0)$ & $0.8(0.6,1.0$ & & & $(0.4,0.9)$ & & & & \\
\hline Moderate to & Control & $2.9(2.3,3$ & & & $(2.6,3.7)$ & $2.9(2.2,3.5$ & & & $(1.8,3.5)$ & $-0.02(-0.0$ & $0.01)$ & -0.02 & $-0.05,0.01)$ \\
\hline & Treatment & $3.0(2.7,3$ & & & $(2.2,3.0)$ & $2.7(2.2,3.2$ & & & $(1.7,2.7)$ & & & & \\
\hline $\begin{array}{l}\text { Physical } \\
\text { Activity }\end{array}$ & $\begin{array}{c}0 \text { Mo } \\
(n=144)\end{array}$ & $\begin{array}{c}4 \text { Mo } \\
(n=94)\end{array}$ & $\begin{array}{l}12 \\
(\mathrm{n}=\end{array}$ & & $\begin{array}{l}24 \text { Mo } \\
(n=65)\end{array}$ & $\begin{array}{c}0 \text { Mo } \\
(n=75)\end{array}$ & & & $\begin{array}{l}12 \text { Mo } \\
(n=48)\end{array}$ & $\begin{array}{l}24 \text { Mo } \\
(n=33)\end{array}$ & Time & Group & Group:Time \\
\hline Recreational & $82 \pm 79$ & $66 \pm 67$ & $87 \pm$ & & $99 \pm 103$ & $94 \pm 76$ & & \pm 77 & $96 \pm 85$ & $97 \pm 102$ & 0.47 & 0.31 & 0.38 \\
\hline Moderate & $80 \pm 66$ & $64 \pm 64$ & $74 \pm$ & & $96 \pm 98$ & $86 \pm 75$ & & \pm 55 & $82 \pm 71$ & $84 \pm 95$ & 0.64 & 0.69 & 0.30 \\
\hline Vigorous & $33 \pm 42$ & $29 \pm 42$ & $41 \pm$ & & $46 \pm 53$ & $37 \pm 39$ & & \pm 41 & $42 \pm 42$ & $49 \pm 54$ & 0.02 & 0.20 & 0.74 \\
\hline $\begin{array}{l}\text { Moderate to } \\
\text { Vigorous }\end{array}$ & $112 \pm 97$ & $93 \pm 88$ & $115 \pm$ & 129 & $142 \pm 137$ & $123 \pm 98$ & 108 & \pm 87 & $125 \pm 102$ & $133 \pm 137$ & 0.17 & 0.48 & 0.37 \\
\hline
\end{tabular}

$\mathrm{Cl}$ indicates confidence interval.

Notes: Linear mixed models were used to calculate $P$ adjusted means data. For Block Kids Physical Activity Survey data, arithmetic data were used to repor mean minutes per day $\pm \mathrm{SD}$ and square root calculations were used to determine $P$. Bold indicates statistical significance $(P \leq .05)$ for both sets of data. 


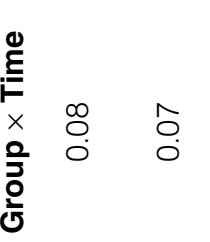

and 24 month) for the $i C o o k 4$ - $H$ program occurred during the summer months (July and August), when youth should not have been accumulating high amounts of sedentary time from being in school.

Environmental factors, which are not readily changed, are also important to consider and have been reported in multiple studies. Taylor and colleagues ${ }^{66}$ conducted a Physical Activity Friendliness Audit and reported that accessibility and safety were predictors of obesity, likely as a result of less PA. A review by Safron and colleagues ${ }^{67}$ also reported that neighborhood crime rates, cost of facilities (gyms, wellness centers, etc), and availably within the community for exercise were all factors that affected PA levels of children and adolescents. In contrast, Comstock and colleagues ${ }^{68}$ reported that in rural areas, there was a lack of association between measured environmental support and the perception of environmental support for PA in youth. Youth's perception of the environment to support PA was associated with greater PA rather than the actual facilities to support PA. Although the current researchers did not measure youth's perception of their PA environment in iCook 4- $\mathrm{H}$, a strength of the iCook 4 - $H$ curriculum activities is that they were designed to be completed in environments with limited environmental support for physical activities. However, in addition to parental involvement, greater input from others in the community may be needed to support enhancements in PA.

Knowledge of PA and skill to perform activities may also be predictors of activity levels. Jaakkola and colleagues $^{69}$ reported that fundamental movement skills, (locomotor, manipulative, and balance skills) and physical fitness (cardiorespiratory endurance and muscle strength) in youth were predictors of PA levels later in life. Cohen and colleagues ${ }^{70}$ also reported a correlation between fundamental movement skills with PA levels and cardiorespiratory fitness. Both studies provided support for improving knowledge and competence of movement as a foundation for increasing PA and decreasing sedentary time. 
One observation seen in the current study was a lack of significant change in objective accelerometerderived data over time but an increase in self-reported VPA in the BKPAS. It is known that self-reported measures of activity are not accurate compared with objective measures owing to overreporting. ${ }^{71,72}$ However, the differences seen in the current study may also indicate that over time, youth perceived that they were more active particularly in VPA than the accelerometer-derived data indicated. This self-reported increase in PA might be caused by a gain in knowledge about the PA that occurs with education in the school systems. In addition, in the self-reported data, the participants may have equated the fact that they were out of school as being more active. The baseline and 12- and 24-month assessments were conducted when participants were out of school and the 4-month assessment occurred during months when participants should have been in school.

A strength of the iCook 4-H program was that it was a control-treatment study with $\geq 50 \%$ of youth PA objectively measured using accelerometers over 24 months. A limitation of this study is that participants were recruited through convenience sampling. Those interested in food and nutrition programs may have responded to recruitment efforts more readily than those uninterested in these types of programs; therefore, results may not be generalizable to the entire population. Although participants were recruited through convenience sampling, they were recruited from geographically different areas across the US.

\section{IMPLICATIONS FOR RESEARCH AND PRACTICE}

Although the iCook 4-H program did not significantly increase PA or decrease sedentary time, youth selfreported an increase in VPA PA and an increase in the number of days per week that they were PA over 24 months, which may have indicated they intended to be more active. The study also observed youth over 2 years, providing longitudinal information about the activity patterns of participants. The iCook $4-H$ program was a multicomponent program with a focus on cooking skills, mealtime behavior, family conversation, and playing together as a family to enhance positive health behaviors through reciprocal role modeling through adult and youth interaction. In iCook 4-H, PA was meant to be incorporated into daily living activities with family involvement, with an overall goal of reducing sedentary time. The youth self-reported more VPA and more days per week of being physically active for 60 minutes; however, these increases were not seen in the accelerometer-measured PA and sedentary time. Therefore, the results of the current study imply that obesity prevention interventions aimed at increasing PA or decreasing sedentary time may need to put greater focus on those specific intended outcomes. It may also be important to focus on identifying barriers to PA and facilitators for sedentary time and creating interventions to combat these barriers and facilitators.

Additional factors to consider for childhood obesity interventions include placing greater emphasis on developing PA skills, as well as teaching youth what constitutes PA. Furthermore, focus might be placed on changing environmental factors and increasing PA both during and after school. Age, sex, and attitude toward activity might also be considered for childhood obesity interventions aimed at PA.

Sedentary time and PA are independent risk factors for obesity and chronic diseases. To increase PA for obesity prevention, it must be of moderately to vigorously intense. Reducing sedentary time may provide another opportunity to prevent childhood obesity within an intervention. Overall, more interventions are needed to prevent the decrease in PA and increase in sedentary time that results as children age into adolescence. More research is needed on specific interventions aimed solely at increasing PA and decreasing sedentary time in youth, as well as youth's intention to be more physically active.

\section{ACKNOWLEDGMENTS}

Funding for this study was provided by Agriculture and Food Research Initiative Grant No. 2012-68001-19605 from the US Department of Agriculture National Institute of Food and Agriculture, Childhood Obesity Prevention: Integrated Research, Education, and Extension to Prevent Childhood Obesity, A2101 and respective state agriculture experiment stations.

\section{REFERENCES}

1. Odgen C, Carrol M, Kit B, Flegal K. Prevalence of childhood and adult obesity in the United States, 2011-2012. JAMA. 2014;311:806-814.

2. Katzmarzyk P, Barlow S, Bouchard C, et al. An evolving scientific basis for the prevention and treatment of pediatric obesity. Int J Obes (Lond). 2014;38:887905.

3. Birch L, Ventura A. Preventing childhood obesity: what works? Int J Obes (Lond). 2009;33(suppl 1):S74-S81.

4. World Health Organization. Facts and figures on childhood obesity. http:// www.who.int/end-childhood-obesity/ facts/en/. Accessed October 3, 2018.

5. American Heart Association. BMI in children. http://www.heart.org/ HEARTOR G/HealthyLiving/HealthyKids/ChildhoodObesity/Overweightin-Children_UCM_304054_Article. jsp\#.V4U_Yvkrjpg. Accessed October 31, 2018.

6. Park M, Falconer C, Viner R, Kinra S. The impact of childhood obesity on morbidity and mortality in adulthood: a systematic review. Obes Rev. 2012;13: 985-1000.

7. McLoone P, Morrison D. Risk of child obesity from parental obesity: analysis of repeat national cross-sectional surveys. Eur J Public Health. 2014;24:186-190.

8. US Department of Health and Human Services. 2008 Physical Activity Guildelines for Americans summary. http:// health.gov/paguidelines/guidelines/summary.aspx. Accessed October 3, 2018.

9. World Health Organization. Physical activity and young people: recommended levels of physical activity for children aged 5-17 years. http://www.who.int/dietphysicalactivity/factsheet_young_people/en/. Accessed October 3, 2018. 
10. Griffiths L, Parsons T, Hill C. Self esteem and quality of life in obese children and adolescents: a systemic review. Int J Pediatr Obes. 2010;5:282-304.

11. National Physical Activity Plan. The 2016 United States Report Card on Physical Activity in Youth. http:// www.physicalactivityplan.org/reportcard/2016FINAL_USReportCard.pdf. Accessed October 31, 2018.

12. Cooper A, Goodman A, Page A, et al. Objectively measured physical activity and sedentary time in youth: the International Children's Accelerometry Database (ICAD). Int J Behav Nutr Phys Act. 2015;12:113-223.

13. Yli-Piipari S, Kulmala J, Jaakkola T, Hakonen H, Fish J, Tammelin T. Objectively measured school day physical activity among elementary students in the United States and Finland. J Phys Act Health. 2016;13:440-446.

14. Troiano RP, Berrigan D, Dodd K, Masse L, Tilert T, McDowell M. Physical activity in the United States measured by accelerometer. Med Si Sports Exerc. 2008;40:181-188.

15. Fakhouri T, Hughes J, Burt V, Song M, Fulton J, Odgen C. Physical activity in US youth aged 12-15 years, 2012. NCHS Data Brief. 2014;141:1-8.

16. Belcher B, Berrigan D, Dodd K, Emken B, Chou C, Spruijt-Metz D. Physical activity in US youth: effect of race/ethnicity, age, gender, and weight status. Med Sci Sports Exerc. 2010;42: 2211-2221.

17. Robert Wood Johnson Foundation. Sedentary behaviors and youth: current trends and the impact on health. https://activelivingresearch.org/sites/ default/files/ALR_Brief_SedentaryBehavior_Jan2014.pdf. Accessed August 26, 2018.

18. Pate R, O'Neill J, Lobelo F. The evolving definition of "sedentary". Exerc Sport Sci Rev. 2008;36:173-178.

19. Daniels S, Hassink S. The role of the pediatrician in primary prevention of obesity. Pediatrics. 2015;136:e275-e292.

20. Brug J, Chinapaw M. Determinants of engaging in sedentary behavior across the lifespan: lessons learned from two systematic reviews conducted within DEDIPAC. Int J Behav Nutr Phys Act. 2015;12:134.

21. Belcher B, Berrigan D, Papachristopoulou A, et al. Effects of interrupting children's sedentary behaviors with activity on metabolic function: a randomized trial. J Clin Endocrinol Metab. 2015;100:3735-3743.

22. Katz D, Cushman D, Reynolds J, et al. Putting physical activity where it fits in the school day: preliminary results of the ABC (activity bursts in the classroom) for fitness program. Prev Chronic Dis. 2010;7:A82.

23. Duvivier B, Schaper N, Bremers M, et al. Minimal intensity physical activity (standing and walking) of longer duration improves insulin action and plasma lipids more than shorter periods of moderate to vigorous exercise (cycling) in sedentary subjects when energy expenditure is comparable. PLoS One. 2013;8:e55542.

24. Hamilton M, Healy G, Dunstan D, Zderic T, Owen N. Too little exercise and too much sitting: inactivity physiology and the need for new recommendations on sedentary behavior. Curr Cardiovasc Risk Rep. 2008;2:292-298.

25. Council on Communications and Media. Media use in school-aged children and adolescents. Pediatrics. 2016; 138: e20162592.

26. Khambalia A, Dickinson S, Hardy L, Gill T, Baur L. A synthesis of existing systematic reviews and meta-analyses of school-based behavioural interventions for controlling and preventing obesity. Obes Rev. 2012;13:214-233.

27. Li X, Lin S, Guo H, et al. Effectiveness of a school-based physical activity intervention on obesity in school children: a nonrandomized controlled trial. BMC Public Health. 2014;14:1282-1283.

28. Weaver S, Kelley L, Griggs J, Weems S, Umstattd Meyer M. Fit and healthy family camp for engaging families in a child obesity intervention: a community health center pilot project. Fam Community Health. 2014;37:31-44.

29. Van Allen J, Borner K, Gayes L, Steele R. Weighing physical activity: the impact of a family-based group lifestyle intervention for pediatric obesity on participants' physical activity. $J$ Pediatr Psychol. 2015;40:193-202.

30. Epstein L, Valoski A, Wing R, McCurley J. Ten-year outcomes of behavioral family-based treatment for childhood obesity. Health Psychol. 1994;13:373-383.

31. Kothandan S. School based interventions and family based interventions in the treatment of childhood obesity-a systemic review. Arch Public Health. 2014;72:3
32. Rausch J, Berger-Jenkins E, Nieto A, McCord M, Meyer D. Effect of a school-based intervention on parents' nutrition and exercise knowledge, attitudes, and behaviors. Am J Health Educ. 2015;46:33-39.

33. Watson P, Dugdill L, Pickering K, et al. Service evaluation of the GOALS family-based childhood obesity treatment intervention during the first 3 years of implementation. BMJ Open. 2015;5: e006519.

34. Sahoo K, Sahoo B, Choudhury A, Sofi N, Kumar R, Bhadoria A. Childhood obesity: causes and consequences. $J$ Family Med Prim Care. 2015;4:187-192.

35. Golan M, Fainaru M, Weizman A. Role of behaviour modification in the treatment of childhood obesity with the parents as the exclusive agent of change. Int J Obes Relat Metab Disord. 1998;22:1217-1224.

36. Birch L, Fisher J. Development of eating behaviors among children and adolescents. Pediatrics. 1998;101(3 part 2): 539-549.

37. Martin-Biggers J, Spaccarotella K, Hongu N, Alleman G, Worobey J, Byrd-Bredbenner C. Translating it into real life: a qualitative study of the cognitions, barriers and supports for key obesogenic behaviors of parents of preschoolers. BMC Public Health. 2015;15: 189.

38. Brown HE, Atkin AJ, Panter J, Wong G, Chinapaw MJM, van Sluijs EMF. Family-based interventions to increase physical activity in children: a systematic review, meta-analysis and realist synthesis. Obesity Rev. 2016;17:345-360.

39. Fagg J, Chadwick P, Cole T, et al. From trial to population: a study of a familybased community intervention for childhood overweight implemented at scale. Int $J$ Obes (Lond). 2014;38: 1343-1349.

40. Altman M, Cahill Holland J, Lundeen $\mathrm{D}$, et al. Reduction in food away from home is associated with improved child relative weight and body composition outcomes and this relation is mediated by changes in diet quality. $J$ Acad Nutr Diet. 2015;115:1400-1407.

41. Williams A, Henley W, Williams C, Hurst A, Logan S, Wyatt K. Systemic review and meta-analysis of the association between childhood overweight and obesity and primary school diet and physical activity policies. Int J Behav Nutr Phys Act. 2013;10:101-123. 
42. Upton P, Taylor C, Erol R, Upton D. Family-based childhood obesity interventions in the UK: a systemic review of published studies. Community Pract. 2014;87:25-29.

43. Golan M. Parents as agents of change in childhood obesity-from research to practice. Int J Pedtr Obes. 2006;1:66-76.

44. Patrick H, Nicklas T. A review of family and social determinants of children's eating patterns and diet quality. $\mathrm{J} \mathrm{Am}$ Coll Nutr. 2005;24:83-92.

45. St. Jeor S, Perumean-Chaney S, Sigman-Grant M, Williams C, Foreyt J. Family-based interventions for the treatment of childhood obesity. $\mathrm{J} \mathrm{Am}$ Diet. 2002;102:640-644.

46. 4-H. What is 4-H? http://4-h.org/ about/what-is-4-h/. Accessed October 3, 2018.

47. Bandura A. Social cognitive theory: an agentic perspective. Annu Rev Psychol. 2001;52:1-26.

48. Franzen-Castle L, Colby SE, Kattelmann KK, et al. Development of the iCook 4$H$ curriculum for youth and adults: cooking, eating, and playing together for childhood obesity prevention. J Nutr Educ Behav. 2019;51:S60-S68.

49. University of Nebraska-Lincoln. Youth in Motion. http://4hcurriculum.unl. edu/index.php/main/program_project/ 85. Accessed October 31, 2018.

50. Bailey RC, Olson J, Pepper SL, et al. The level and tempo of children's physical activities: an observational study. Med Sci Sports Exerc. 1995;27:1033-1041.

51. Banda JA, Haydel KF, Davila T, et al. Effects of varying epoch lengths, wear time algorithms, and activity cut-points on estimates of child sedentary behavior and physical activity from accelerometer data. PLoS One. 2016;11:e15034.

52. Aadland E, Andersen LB, Sigmund AA, Resaland GK. A comparison of 10 accelerometer non-wear time criteria and logbooks in children. BMC Public Health. 2018;18:323.

53. Jaeschke L, Luzak A, Steinbrecher A, et al. 24 h-accelerometry in epidemiological studies: automated detection of non-wear time in comparison to diary information. Sci Rep. 2017;7:2227.

54. Rich C, Geraci M, Griffiths L, Sera F, Dezateux C, Cortina-Borja M. Quality control methods in accelerometer data processing: defining minimum wear time. PLoS One. 2013;8:e67206.

55. Matthews CE, Ainsworth BE, Thompson RW, Bassett Jr DR. Sources of variance in daily physical activity levels as measured by an accelerometer. Med Sci Sports Exerc. 2002;34:1376-1381.

56. Gretebeck RJ, Montoye HJ. Variabliity of some objective measures of physical activity. Med Sci Sports Exerc. 1992;24: 1167-1172.

57. Evenson K, Catellier D, Gill K, Ondrak K, McMurray R. Calibration of two objective measures of physical activity for children. J Sports Sci. 2008;26: 1557-1565.

58. Katapally TR, Muhajarine N. Towards uniform accelerometry analysis: a standarization methodology to minimize measurement bias due to systematic accelerometer wear-time variation. J Sports Sci Med. 2014;13:379-386.

59. NutritionQuest. Block Kids Physical Activity Screener. https://nutritionquest.com/company/our-researchquestionnaires/. Accessed October 31, 2018.

60. Trost SG, Loprinzi PD. Parental influences on physical activity behavior in children and adolescents: a brief review. Am J Lifestyle Med. 2011;5:171-181.

61. Vanhelst J, Fardy P, Beghin L, BuiXuan G, Mikulovic J. Strategies in intervention programmes for obese youth: implication of the age and the type of physical activities. Clin Physiol Funct Imaging. 2015;35:17-20.

62. Jago R, Sebire S, Davies B, et al. Increasing children's physical activity through a teaching-assistant led extracurricular intervention: process evaluation of the action 3:30 randomised feasibility trial. BMC Public Health. 2015;15:156.

63. National Center for Education Statistics. Schools and staffing survey (SASS), 2007-2008. https://nces.ed.gov/surveys/sass/tables/sass0708_035_s1s.asp. Accessed October 3, 2018.

64. Chriqui F, Resnick E, Schneider L, Schermbeck R, Adcock T, Carrion V, Chaloupka F. School District Wellness Policies: Evaluation Progress and Potential for Improving Children's Health Five Years
After the Federal Mandate. School Years 2006-07 Through 2010-11, Vol 3. Chicago, IL: Bridging the Gap Program, Health Policy Center, Institute for Health Research and Policy, University of Illinois at Chicago; 2013.

65. Sherman C, Tran C, Alves Y. Elementary school classroom teacher delivered physical education- costs, benefits, and barriers. Physical Educator. 2010;67: 2-17.

66. Taylor W, Upchurch S, Brosnan C, et al. Features of the built environment related to physical activity friendliness and children's obesity and other risk factors. Public Health Nurs. 2014;31: 545-555.

67. Safron M, Cislak A, Gaspar T, Luszczynska A. Micro-environmental characteristics related to body weight, diet, and physical activity of children and adolescents: a systematic umbrella review. Int $J$ Environ Health Res. 2011;21:317-330.

68. Comstock C, Kattelmann K, Zastrow $\mathrm{M}$, et al. Assessing the environments for support of youth physical activity in rural communities. J Nutr Educ Behav. 2016;48:234-241.

69. Jaakkola T, Yli-Piipari S, Huotari P, Watt A, Liukkonen J. Fundamental movement skills and physical fitness as predictors of physical activity: a 6-year follow-up study. Scand J Med Sci Sports. 2016;26:74-81.

70. Cohen K, Morgan P, Plotnikoff R, Barnett L, Lubans D. Improvements in fundamental movement skill competency mediate the effect of the SCORES intervention on physical activity and cardiorespiratory fitness in children. J Sports Sci. 2015;33: 1908-1918.

71. Celis-Morales C, Perez-Bravo F, Ibanez L, Salas C, Bailey M, Gill J. Objective vs. self-reported physical activity and sedentary time: effects of measurement methods on relationships with risk biomarkers. PLoS One. 2012; 7: e36345.

72. Kavanaugh K, Moore J, Hibbett L, Kaczynski A. Correlates of subjectively and objectively measured physical activity in young adolescents. J Sport Health Sci. 2015;4:222-227. 